\title{
PART III ACADEMIC LIFE: REALITIES AND POSSIBILITIES
}

$T_{\text {he first two articles in this section report results of intensive interview }}$ studies with dozens of faculty. Hageseth and Atkins note connections between the institutional context and the quality of faculty life. Sorcinelli documents the joys and frustrations of new faculty, and describes programs at her institution to support faculty during their first few years on campus.

Studies of academic life reveal numerous stresses associated with the "eternal triangle" of teaching, research, and personal life. Boice's study examines the widely held view that faculty do not have time to write on the job. He reports a study comparing the work patterns of two groups of faculty experiencing new pressures for scholarly publication: traditional faculty on campuses where such pressures are increasing, and library faculty. Although scholarly activity is a pervasive aspect of faculty life, reviewers found this article troubling, perhaps because POD has not traditionally addressed the importance of scholarship in faculty development work. Boice's work challenges us to expand the boundaries of our professional role definition to include this central and often difficult area of faculty life. It also suggests a window of opportunity for renewing professional vitality of faculty.

Thompson, Turner, and Boice take a hard look at what we know about academic life, and offer some "insider's advice" to new faculty. While not everyone will agree with their assessment of the situation, their suggestions offer a good starting point for discussion about new faculty survival on any given campus.

Finally, we offer a description and analysis of one of the most remarkable faculty development programs in the country. The Washington Center, housed at The Evergreen State College in Washington State, facilitates faculty exchanges for a specific purpose: collaborative teach- 
ing. The program builds statewide community among teachers, and unleashes energy enough to revitalize teaching in enduring ways.

Taken together, these articles provide ample food for thought and discussion about the quality of academic life and what might be done to enhance it. 